\title{
Reduplikasi Upacara Adat Bapelas Sebagai Simbol Kekuasaan Kerajaan Kutai Kartanegara
}

\author{
Emmy Sundari, Reiza D Dienaputra, Awaludin Nugraha dan Susi Yuliawati \\ Kajian Budaya, Fakultas Ilmu Budaya \\ Universitas Padjajaran \\ 082218104188, antoinette.emmy2002@gmail.com
}

\begin{abstract}
The subject of this research is the Bapelas ceremony. Object of discussion about reading the symbols of power contained in the Bapelas ceremony. The reading of this symbol is done in the form of reduplication and direct observation about the structure of the implementation of the Bapelas ceremony. This assesement is done through collecting data empirically, researchers become part in the ceremony. Research conducted inductive in nature. This study uses qualitative methods and analysis of descriptive analytic. The reduplication of Bapelas ceremony is the repetition of the ceremony. The ceremony of ancestral heritages orally every year (Form of ceremony). Bapelas Ceremony store lot of ceremonial symbols of power of a sultan as holders of power in the Kingdom of Kutai. However, the sultan himself did not hold power and authority in the government of the Republic of Indonesia. In ancient times the King of Kutai Kartanegara as holders of power and authority as a whole. There is a turn of the power, the power of the Kingdom into government power of the Republic of Indonesia. Authority and power only as a symbol of legitimacy or recognition that the Kingdom of Kutai Kartanegara still stands. The Government of Indonesia has made it as a cultural heritage (local wisdom) and tourism for economic progress, social, and political Kutai Kartanegara.
\end{abstract}

Keywords: Bapelas, simbol, power.

\begin{abstract}
ABSTRAK
Subjek penelitian ini adalah upacara adat Bapelas. Objek pembahasannya tentang pembacaan simbol-simbol kekuasaan di upacara adat Bapelas. Pembacaan simbol dilakukan dalam bentuk reduplikasi dan pengamatan langsung struktur pelaksanaan upacara adat Bapelas. Pengkajian ini dilakukan melalui pengumpulan data-data secara empiris, bersifat induktif, menggunakan metode kualitatif dan analisis interpretatif. Reduplikasi upacara adat Bapelas merupakan pengulangan upacara ritual-sakral warisan leluhur secara turun-temurun dari tahun ke tahun. Upacara adat Bapelas menyimpan banyak simbol-simbol yang mencerminkan kekuasaan sultan sebagai pemegang kekuasaan di Kerajaan Kutai. Namun sultan sendiri tidak memegang kekuasaan dan wewenang di masa pemerintahan Republik Indonesia. Kekuasaan dalam penelitian ini, hanya sebatas kekuasaan sultan sebagai pemegang kekuasaan adat di kerajaan. Kekuasaan dan wewenang hanya sebagai simbol legitimasi atau pengakuan bahwa Kerajaan Kutai Kartanegara sampai saat ini masih berdiri. Pemerintah Indonesia menjadikan Kerajaan ini sebagai warisan budaya (kearifan lokal) dan pariwisata bagi kemajuan ekonomi, sosial, dan politik Kutai Kartanegara .
\end{abstract}

Kata Kunci: Bapelas, simbol, kekuasaan. 


\section{PENDAHULUAN}

Upacara adat Bapelas dilaksanakan di Kutai Kartanegara sebagai penghormatan terhadap leluhur. Upacara adat Bapelas merupakan upacara ritual-sakral dalam pelaksanaan upacara besar kenegaraan “Pengakuan Kuasa Sultan”. Upacara adat Bapelas ini dipimpin oleh seseorang yang mendapatkan kepercayaan penuh dari sultan Kutai yang disebut belian. “Upacara adalah peristiwa bersama. Ada pemimpin upacara, pelaku upacara, dan peserta Upacara" (Sumardjo, 2010, hlm. 117). Penyelenggaraan Upacara adat Bapelas dimaksudkan untuk memuja raga dan sukma sultan secara keseluruhan sehingga sultan mampu menyandang kekuatan dan kekuasaan dalam memangku adat Kutai Kartanegara. Eksistensi seorang sultan atau raja dapat terlihat ketika sultan mengikuti jalannya upacara adat Bapelas dari awal hingga akhir pelaksanaan upacara. Sultan pada upacara Bapelas berperan sebagai tokoh utama dalam alur proses pelaksanaan Upacara.

Kekuasaan sultan merupakan kekuasaan tertinggi di Kerajaan Kutai Kartanegara. Zaman dulu, masyarakat Kutai menganggap Sultan Kutai sebagai utusan dewa penguasa semesta raya. Raja atau sultan terdahulu dianggap sebagai orang keturunan dewa yang suci atau makhluk astral yang dianggap empunya kekuataan tertinggi. Mitos masyarakat Kutai mengenai kepercayaan sultan sebagian jiwanya adalah dewa, myth atau mitos adalah sejarah mengenai apa yang terjadi pada permulaan waktu. Mitos membangun kebenaran absolut ( Eliade, 2002, hlm. 94). Sisi ini menunjukan bahwa cerita mitos pada upacara Bapelas masih melekat kuat dan belum ada pemisahnya secara jelas subjek dan objeknya sehingga Keyakinan dan kepercayaan masyarakat melebur menjadi satu. Konsep mengenai adanya dewa-dewa tertinggi sebagai sumber kekuasaan dan kekuatan dalam memegang adat merupakan kebutuhan manusia akan penjelasan tentang semua gejala dalam dunia visual maupun dunia emosional, sehingga sultan ingin membenarkan dirinya sebagai pusat mikrokosmos manusia, sebagai pengemban kekuasaan mutlak atas kerajaan duniawi (Moertono, 1985, hlm 7). Kekuasaan yang dimiliki sultan yang terjadi di kehidupan nyata dianggap sebagai kekuasaan yang berasal dari kekuatan dunia atas yang tidak terbatas.

"Kekuasaan raja adalah proyeksi kekuasaan Allah" ( Moedjanto, 1987, hlm. 12). Kutai di jaman sekarang memegang erat keyakinan agama islam, namun kepercayaan dan keyakinan akan hal tentang dewadewa dan shanghiyang masih banyak yang mempercayai. "Kekuasaan dapat bersumber dari kepercayaan dan keyakinan"(Budiarjo, 1984, hlm.13). Maka, bagi masyarakat Kutai sendiri hal tersebut tidak bertentangan dengan keyakinan yang dipegang sekarang dan kehidupan mendatang. Raja atau sultan meski sekarang bukanlah pemegang kekuasaan secara hakiki, namun masyarakat percaya bahwa titah sultan turun dari langit. Sultan atau raja adalah penguasa mutlak pada daerah kekuasaannya. (Moedjanto, 1987, hlm. 122). Raja orang yang mulia, turun menurun memang asalnya raja. (Bachroel, 2009, hlm. 4). Kepercayaan yang tinggi dari masyarakat Kutai Kartanegara kepada sultan yang 
memegang kekuatan dan kekuasaan adat, mendukung pelanggengan kekuasaan sultan di kesultanan. Pelaksanaan upacara adat Bapelas tidak bisa terlepas dari upacara besar Erau. Upacara Erau merupakan upacara rakyat, dari rakyat oleh rakyat dan untuk rakyat. Erau sendiri memiliki arti yaitu riuh, ramai, bersuka ria. Upacara adat Bapelas merupakan bagian integral dari peristiwa budaya Erau. Upacara adat Bapelas dilaksanakan pada malam hari selama 7 malam, sedangkan Erau-nya sendiri dilaksanakan pada siang dan malam hari selama 7 hari. "Upacara terjadi di ruang dan waktu transenden, disini dan sekarang. Waktu lampau menyatu dengan waktu sekarang" (Sumardjo, 2010, hlm. 117). Keduanya dilaksanakan ditempat yang berbeda, yaitu Bapelas dilaksanakan di dalam Keraton Kutai Kartanegara, sedangkan perayaan Erau dilaksanakan di luar Keraton Kutai Kartanegara, seperti: lapangan, alun-alun kota, atau jalan-jalan besar. Upacara Erau ini, dilaksanakan untuk dedikasi dan eksistensi masyarakat Kutai Kartanegara secara keseluruhan, sehingga upacara Erau diganti menjadi Festival Erau yaitu Erau International FolkArtFestival (EIFAF) oleh Dinas Kebudayaan dan Pariwisata Kabupaten Kutai Kartanegara. Upacara adat Bapelas merupakan upacara adat untuk sultan dalam arti memuja sukma dan raga seorang sultan dimulai dari betis, teloran, lutut, paha, pinggang, dada, bahu, tangan, siku, lengan dan kepala agar sukma dan raga seorang sultan mampu menyandang kekuatan dalam kuasa dan kekuatan dalam adat. Upacara ini dilaksanakan satu atau dua tahun sekali selesai memotong padi (Bachroel, 2002, hlm. 150). Simbol kekuasaan pada upacara adat Bapelas terdapat pada beberapa perlengkapan yang mendukung upacara adat dan perilaku sultan pada proses pelaksanaan upacara. Adapun properti yang digunakan pada pelaksanaan upacara ini adalah: tali juwita, cinde, pohon ayu, gong, dan beberapa perlengkapan lainnya. Reduplikasi upacara adat Bapelas dilakukan oleh pihak Keraton Kutai Kartanegara dan didukung sepenuhnya oleh pemerintah daerah. Tujuan pemerintah sebagai daya tarik wisata.

Penelitian ini, menjelaskan tentang tahapan-tahapan pelaksanaan upacara adat Bapelas secara terperinci dengan tujuan memberikan pemahaman bahwa reduplikasi yang terjadi dari jaman dahulu hingga sekarang tidak mengalami perubahan, sehingga penjelasan mengenai pembacaaan relasi simbol-simbol yang memiliki makna upacara adat Bapelas sebagai simbol kekuasaan sultan Kutai dapat diterima dengan jelas.

Penulisan artikel ini, diharapkan memiliki signifikansi dan kontribusi dalam pengembangan kajian budaya; terutama pada upacara adat Bapelas bagi masyarakat umum dan dunia akademik pada khususnya, diharapkan hasil penelitian ini, menjadi referensidaninspirasidalammemaknaisimbolsimbol budaya yang terus dipertahankan. Selain itu juga, penelitian yang dilakukan ini dapat menjadi pendorong pelestarian dan perkembangan budaya pariwisata di wilayah Kutai Kartanegara pada khususnya dan Indonesia pada umumnya, sehingga bermanfaat bagi berbagai kepentingan. Upacara adat Bapelas dapat dijadikan sumber penelitian untuk perkembangan ilmu pengetahuan tidak hanya di bidang seni 
budaya, tetapi juga dapat dipelajari sebagai ilmu pengetahuan di bidang lain. Penelitian ini menggunakan landasan teori Turner karena Turner menyingkapkan tentang processual symbolicanalysis. Symbolic theory (comprehend the symbolic meaning presented), yaitu memahami relasi dan makna simbol yang disajikan pada proses pelaksanaan upacara ritual. Simbol berupa properti, kostum, peserta, dan arena (Turner, 1967, hlm.117).

Teori ini memberikan gambaran tentang makna dan relasi simbol dalam upacara adat Bapelas sebagai pengalaman biologi primodial seorang sultan diakui memiliki kekuasaan dan memegang adat istiadat di Kerajaan Kutai Kartanegara. Turner mengungkapkan bahwa ada interaksi dialektis antara masyarakat keseluruhan dan kelompokkelompok tertentu di dalamnya. Menurut Turner, dualitas dalam mengatur kelompokkelompok sosial yang Turner temukan disimbolkan dengan cara yang berarti melalui praktik-praktik upacara ritual yang membawa makna rangkap. Interaksi (simbolik) dialektis yang terjalin pada Bapelas tampak pada benda-benda simbolik dan prilaku sultan dalam pelaksanaan upacara adat Bapelas, di mana ada kelompok komunal yang memiliki keyakinan dan hasrat untuk menunjukkan bahwa sebuah kekuasaan tertinggi masih dipegang oleh kesultanan Kutai Kartanegara yang memegang peranan penting dalam mengatur kelompok-kelompok sosial kehidupan masyarakat Kutai Kartanegara itu sendiri. Keunggulan teori ini, lebih membahas sebuah simbol sebagai eksistensi pengakuan terhadap diri sendiri sebagai hal yang menonjol di upacara adat Bapelas tersebut, agar lebih diakui oleh kelompok-kelompok komunal atau masyarakat luas (kuasa sultan).

\section{METODE}

Metode yang digunakan untuk mengkaji pembacaan makna simbol yang menunjukkan upacara adat Bapelas sebagai simbol kekuasaan sultan adalah metode kualitatif-induktif. Alat analisis yang digunakan dalam penelitian ini, adalah analisis struktural-interpretatif. Analisis ini digunakan untuk pembacaan relasi simbol-simbol pada upacara adat Bapelas yang mengarah pada indikasi kuasa sultan. Kemudian hasil analisis ditafsirkan sesuai interpretasi pemikiran masyarakat lokal dan kolaborasi instrumen kunci. Pendekatan struktural digunakan untuk membedah gagasan relasi yang terdapat di antara simbol-simbol upacara yang mengarah pada pembacaan kuasa sultan.

Penulis sebagai instrumen kunci mengumpulkan sendiri data melalui dokumentasi, observasi perilaku, dan wawancara dengan para partisipan. Peneliti mendapatkan beragam data dengan cara terlibat langsung pada proses pelaksanaan upacara. Penulis sebagai peneliti membangun pola-pola, kategori-kategori dan temanya dengan cara me-review semua data, diolah secara berulang-ulang sehingga peneliti membangun serangkaian makna tentang simbol kuasa sultan.

\section{HASIL DAN PEMBAHASAN}

Reduplikasi upacara adat Bapelas memiliki struktur dalam proses pelaksanaan- 
nya sehingga simbol-simbol yang terdapat pada properti dan kostum menunjukkan makna. Posisi Upacara adat Bapelas berada dalam satu paket festival Erau (EIFAF). Erau berasal dari kata eroh yang berarti ramai, riuh, ribut, bersuka cita, bergembira, dan suasana riang rendah suara. Memiliki arti banyaknya kegiatan sekelompok orang yang mempunyai hajat dan mengandung makna baik yang bersifat sakral, ritual, maupun hiburan. Pada zaman dahulu

Erau terdiri dari dua macam yaitu Erau Batu Samban dan Erau Tepong Tawar. (1) Erau Batu Samban adalah erau yang pelaksanaannya berlangsung selama 21 hari dan 21 malam. Sultan di pelas dua kali, yaitu: Bapelas pertama dilakukan berayun papan dan Bapelas kedua berayun di dekat pinang Ayu (Tombak Sangkoh Piatu). (2) Erau Tepong Tawar adalah Erau yang pelaksanaannya berlangsung selama 7 hari dan 7 malam. Pada Erau tepong tawar sultan di pelas dengan berjalan kaki di atas tapak leman mengarah ke pohon Ayu. Upacara tradisi budaya Erau pada masa sekarang adalah Erau Tepong Tawar. Pada Erau ini, terdapat beberapa upacara pokok yang dianggap penting oleh kesultanan yang tidak boleh dihilangkan. Adapun upacara pokok tersebut adalah Menjamu benua; Mendirikan pohon Ayu; Adat Kutai; Menyisihkan Lembuswana dan tambak karang; Beluluh, Bekanjar, dan Beganjur; Seluang mudik; Belian bekenjong; Bapelas; Belimbur; Ziarah makam Aji Imbut; Ziarah ke Kutai Lama. Bapelas berasal dari kata $\mathrm{Ba}$ dan pelas, ba berarti mengerjakan, dikerjakan, sedangkan pelas berarti syukur/bersyukur/syukuran. Perayaan syukuran seperti kelahiran bayi; pemberian gelar; tijak tanah bayi memasuki usia batita.
Perayaan syukuran lahirnya Sultan Kutai ditandai dengan dentuman meriam yang dilakukan sebanyak tujuh kali tujuh hari pada malam hari (seminggu berturut-turut). Perayaan kelahiran sultan Kutai, di Erau-kan oleh masyarakat setempat.

Kelahiran sultan yang ditandai oleh turunnya dewa adalah bagian dari pola pemikiran masyarakat Kutai pada masa itu dan masih dipercaya hingga kini. Kekuasaan seorang raja yang merupakan titisan shanghiyang berpengaruh kuat pada rakyat Kutai dan daerah kekuasaan sultan Kutai, sebelum pemerintah Republik Indonesia masuk dalam pemerintahan Kutai Kartanegara, kekuasaan sultan dianggap absolut (mutlak).

\section{Tahapan Upacara Bapelas}

1. Tahap Persiapan

Pada upacara Bapelas menggunakan sesaji yang wajib dipakai yaitu: wijen, beras kuning, air beras kuning, dupa setanggi, air kembang, kain kuning, dan peludahan. Sesaji ini ditempatkan pada wadah atau mangkok yang terbuat dari tembaga atau logam yang disebut capah. Kelengkapan sesaji tidak boleh ada yang tertinggal satu pun, karena dianggap akan mendatangkan malapetaka dan upacara tidak akan berjalan dengan lancar. Pada tahap persiapan ini, jenis-jenis sesaji yang digunakan terdiri dari; wijen (biji wijen berbentuk segitiga/lancip, simbolis menuju dunia atas. Biji wijen berfungsi untuk mengundang para Sanghiyang, kemumulan dan kejuntaian), weja/beras kuning (beras yang diberi warna kuning, berasal dari kunyit. Simbol dari kemakmuran/produktif), air beras kuning (simbol kerendahan hati, air memiliki sifat 


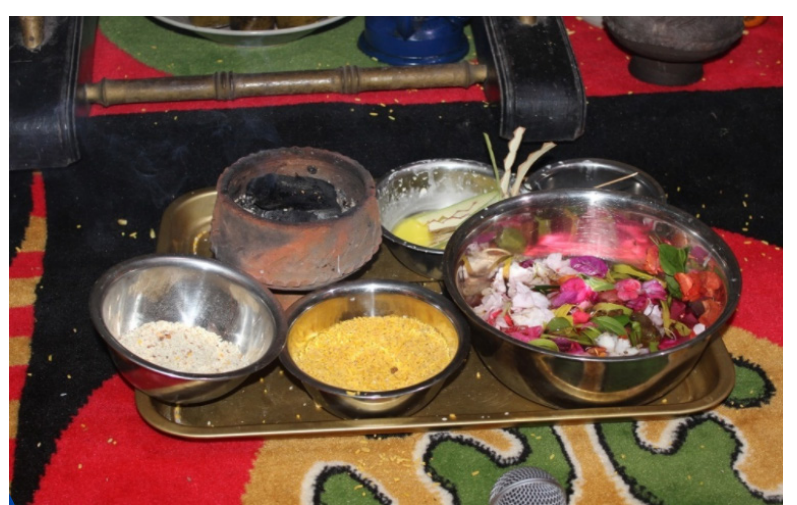

Gambar 1. Sesaji sebagai syarat untuk pelaksanaan Upacara Bapelas

(Sumber: Koleksi Penulis, 15 Juni 2014)

selalu mencari tempat yang lebih rendah dan kesejahteraan), air kembang (sebagai simbol pembersihan noda/menyucikan area upacara, sebagai sumber kehidupan makhluk), dupa setanggi (simbol penyatuan dunia atas dan bawah/lambang pertemuan makhluk dunia atas dan bawah, sebagai pembasmi segala kotoran dari roh jahat, sebagai saksi upacara), kain kuning (Simbol dari matahari. Matahari sebagai sumber kehidupan bagi manusia, energi, kebahagiaan, kebijaksanaan, harapan, loyalitas, keagungan, idealisme dan optimisme).

Makna simbol sesaji pada tahap persiapan menggambarkan bahwa tempat atau keadaan sebagai wadah berlangsungnya Bapelas harus dalam kondisi suci, bersih, dan terlepas dari anasir-anasir negatif. Tujuannya agar sanghiyang sebagai pemilik kekuasaan dunia atas dapat turun ke bumi untuk ikut dalam proses upacara (lihat Gambar 1).

\section{Tahap Pelaksanaan}

Ruangan Puri tamu untuk pelaksanaan Bapelas harus bersih dan sunyi. Kemudian kepala adat keraton mengadakan sawai (proses komunikasi dengan makhluk astral). Proses sawai merupakan proses izin dunia atas untuk pelaksanaan upacara. Adapun proses Bapelas dilakukan dengan cara: (a) bungkusan kain kuning yang ada dirobek, Pinang Ayu dibuka. Tali Juwita dan Kain Cinde direntangkan ke arah barat dan di ujungnya dipegang oleh keluarga sultan yang sudah ditunjuk. (b)Belian (dukun keturunan dewa) mulai membacakan mantranya (bememang) rebak ayu, memberitahukan kepada para kemumulan (kumpulan orang-orang gaib), sanghiyang dan orang-orang halus lainnya bahwa Bapelas segera akan dimulai. (c) Belian memasuki puri Sultan (kamar) yang berada di bawah tangga belakang puri tamu, didampingi anak dan kerabat Sultan yang ditunjuk dan Pangkon pembawa Damar jujagat dengan diiringi irama suling oleh penyuling untuk membawa Sultan pergi Bapelas ke ruang puri tamu. (d) Sultan berjalan menuju puri tamu diiringi lagu gamelan yaitu lagu Serseh. Sultan berjalan menuju Tapak Leman (kain kuning yang bentuknya menyerupai kapak terbuat dari kain cinde yang dianyam menyerupai bentuk naga, panjangnya 2 meter dan lebarnya 0,5 meter ditautkan dengan kepingan-kepingan terbuat dari emas yang digelar di lantai mengarah ke Gong Raden Galoh), di sebelah kiri tapak leman sudah siap Pangkon (dayang atau bidadari yang mengiringi dewa) membawa peludahan, penangan, mandau, tombak, keris, di sebelah kanan duduk pula pangkon membawa keris Burikkang, penginangan perak, dan lainlain. (e) Setelah kepala adat besawai (meminta izin kepada roh-roh gaib untuk pelaksanaan Upacara Bapelas), gamelan berbunyi dengan lagu yang berjudul Ireng-ireng, gong besar dibunyikan, maka sultan meniti tapak leman 


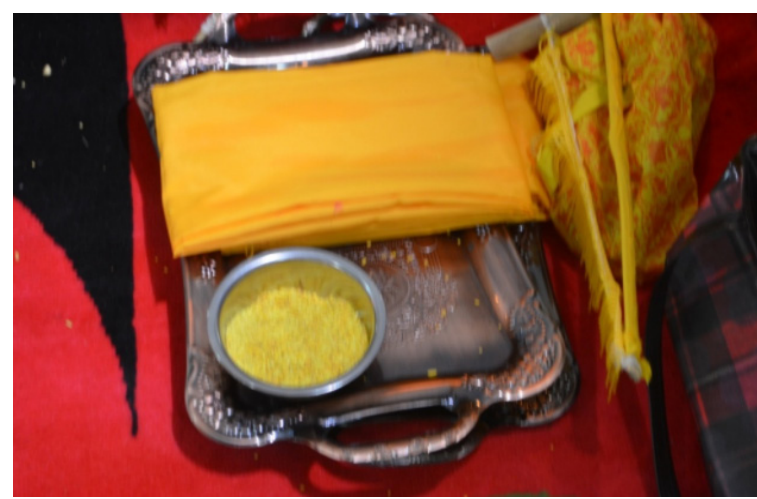

Gambar 2. Sesaji atau syarat untuk Upacara Bapelas (Sumber: Koleksi Penulis, 15 Juni 2014)

yang didahului dengan menginjak sebuah batu/karang sebagai pijakan. (f) Tangan kanan Sultan memegang rentangan tali Juwita yaitu benang yang berlapis tujuh lapis berwadah cincin (tali yang berbentuk lingkaran kecil) menunjukkan bahwa masyarakat Kutai Kartanegara itu berlapis-lapis atau bergolonggolong. (g) Tangan kiri sultan memegang tali cinde yang berwarna kuning yang memiliki arti memegang atau memelihara keluarganya, kuning memiliki arti kesucian. Hal ini, menunjukkan bahwa seorang raja harus mengutamakan kepentingan rakyat terlebih dahulu kemudian kepentingan keluarganya. (h) Sultan berjalan menuju Gong Raden Galoh yang dilapisi kain kuning. Gong diinjak Sultan bersamaan dengan bunyi meriam meledak yang memiliki arti bahwa bersatunya tiga kekuatan yaitu Raja, rakyat, dan keluarga. Ketiga kekuatan ini dipercaya selalu bersama dan kekuatan ini memiliki arti sebagai kedaulatan atau penjaga kesejahteraan dan kemakmuran bumi etam. (i) Sultan memutar kekanan tanpa melepas pegangan kedua tangan, hal itu menunjukkan bahwa hubungan rakyat, keluarga, dan seorang Raja tidak akan pernah terputus. (j) Sultan berjalan kembali di atas tapak leman menuju kursi singgasana

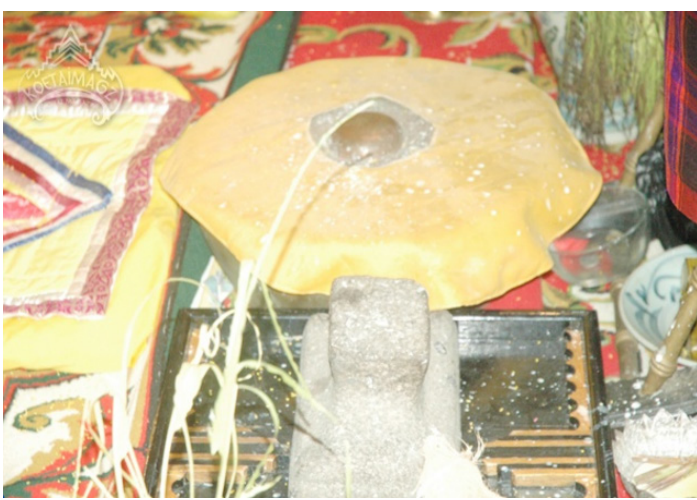

Gambar 3. Gong Raden Galoh dan Batu Tijakan (Sumber: Budpar, Kutai Kartanegara, 2012)

kerajaan Kutai Kartanegara.

Makna dan simbol pada tahap pelaksanaan, sangat jelas tercermin bahwa upacara adat Bapelas sebagai wadah pelanggengan kekuasaan sultan. Oleh sebab itu, penulis selaku instrumen kunci dalam penelitian ini, menjelaskan secara deskripsi dan terperinci disertai tabel yang menjelaskan makna dan simbol kekuasaan yang terdapat pada tahap pelaksanaan upacara adat Bapelas (lihat Gambar 2). Properti yang digunakan sebagai simbol kekuasaan pada tahap pelaksanaan bisa diihat pada tabel 1 .

\section{Tahap Penutupan}

Setelah Sultan menginjakkan kakinya ke Gong Raden Galoh (lihat Gambar 3) dan menyentuh tijakan maka meriam meledak sebanyak tujuh kali. Bunyi dentuman meriam sebanyak tujuh kali itu menandakan bahwa upacara Bapelas telah selesai. Maka, Festival Erau sudah bisa dimulai. Sultan pun menuju puri atau ruang makan untuk menjamu para tamu undangan dari dalam dan luar negeri. Makna dari simbol tijak Gong Raden Galoh dan tijak batu karang adalah bahwa titah sultan wahyu dari dewa tertinggi dan mutlak dilaksanakan. 
Tabel 1. Arti Properti Sebagai Simbol

\begin{tabular}{|c|c|}
\hline Properti/simbol & Arti \\
\hline Pohon /tiang ayu & $\begin{array}{l}\text { Pohon ayu disebut juga sebagai "sangkoh pintu" yang memiliki } \\
\text { arti mendirikan kebenaran yang tersurat maupun kebenaran yang } \\
\text { tersirat, memiliki kekuatan magis dan memancarkan kekuatan } \\
\text { spriritual. }\end{array}$ \\
\hline Tali juwita & $\begin{array}{l}\text { Merupakan simbol dari kekuasaan Sultan Kutai Kartanegara yang } \\
\text { berpusat di sungai Mahakam dialiri air yang sangat deras mengalir } \\
\text { ke laut, beranak sungai bercabang tujuh dan kekuasaan sultan } \\
\text { meliputi beberapa negeri di sekitar sungai. }\end{array}$ \\
\hline Kain Cinde & $\begin{array}{l}\text { Simbol adat yang diadatkan dari kerajaan Kutai Kartanegara yang } \\
\text { masih dipegang dan ditaati di dalam negerinya, dan merupakan } \\
\text { simbol kerukunan para kerabat. }\end{array}$ \\
\hline $\begin{array}{l}\text { Janur, daun sirih, } \\
\text { buah pinang }\end{array}$ & $\begin{array}{l}\text { Merupakan simbol bahwa alam dan hutannya memberikan hasil } \\
\text { kemakmuran yang berlimpah ruah bagi rakyat Kutai. Sumber alam } \\
\text { bagi masyarakat kutai merupakan harta karun yang paling besar } \\
\text { memberi kesejahteraan. }\end{array}$ \\
\hline Tapak leman & $\begin{array}{l}\text { Simbol bahwa kekuasaan terbesar di kerajaan Kutai adalah sultan, } \\
\text { sultan merupakan manusia keturunan dewa yang memiliki jiwa } \\
\text { yang suci, berjalan diatas kebenaran dan keadilan. Sultan adalah } \\
\text { pengayom rakyat. }\end{array}$ \\
\hline Pinggan tuha & $\begin{array}{l}\text { Simbol petuah, nasehat, serta petunjuk dari orang-orang tua dahulu } \\
\text { bahwa pohon Ayu harus dilestarikan pada generasi yang akan } \\
\text { dating. }\end{array}$ \\
\hline $\begin{array}{l}\text { Gong Raden Galoh } \\
\text { dan tijakan }\end{array}$ & $\begin{array}{l}\text { Kedua benda ini memilki simbol bahwa perintah sultan juga perintah } \\
\text { dewa. Titah sultan dianggap sebagai wahyu dari dewa tertinggi. } \\
\text { Pijakan sultan pada gong dan batu tijakan adalah simbol bahwa } \\
\text { semua titah sultan adalah mutlak. }\end{array}$ \\
\hline
\end{tabular}

Implikasi upacara adat Bapelas sebagai simbol kekuasaan sultan

Pada praktik upacara Bapelas di atas terdapat simbol dualitas, pola tiga bagi masyarakat Kutai. Hubungan kuasa langit, manusia dan bumi menjadi hal yang penting dalam kehidupan. "Langit dan bumi itu memiliki daya-daya transenden yang tidak dipunyai oleh manusia di muka bumi. Dayadaya itu realitas yang tak dimiliki manusia. Realitas langit dan bumi itu sama dengan realitas manusia, bukan sekedar daya-daya 
akodrati tanpa bentuk. Masyarakat peladang percaya bahwa langit ada masyarakatnya, di bumi ada masyarakatnya" (Jakob, 2010, hlm. 243) .

Struktur upacara dan perilaku sultan yang berupa simbol menunjukkan kuasa sultan masih berlaku di kalangan kesultanan. Pembacaan simbol-simbol pada upacara Bapelas yang mengindikasi pada kekuasaan menjadi kesatuan tiga yaitu: kekuasaan atas, tengah, dan bawah. Langit, manusia, dan bumi. Bahwa sultan bukan hanya berkuasa di dunia bawah namun juga diakui dunia atas, dunia dewa-dewa. Penyatuan dari ketiga hal tersebut dapat diasumsikan sebagai elemen, unsur, dan bagian sehingga upacara merupakan wadah pertemuan tiga kuasa. Konteks tempat atau kedudukan dari simbol dalam upacara menentukan corak hubungannya secara konseptual dengan sistem simbolik dari upacara itu sendiri sebagai keseluruhan.

Makhluk-makhluk astral dunia atas dapat mengunjungi dunia bawah, begitu pula manusia dunia bawah dapat mengunjungi dunia atas. Kosmos yang terdiri dari tiga dunia bersatu agar kehidupan alam semesta dapat dipertahankan dan menjadi bentuk simbolis yang diperlukan untuk menjaga keberlangsungan hidup masyarakat yang teratur, makmur, dan sejahtera. Hakekat bentuk simbolik mendasar dan kuat serta tersebar luas dalam kehidupan manusia adalah karena simbol-simbol itu bersumber pada alam semesta dan hakekat asal mula manusia yang dinamakan sebagai "pengalaman biologi yang primodial". Organisme tubuh manusia yang bersama-sama dengan "pengalaman yang penting serta penuh dengan makna"
Bagan 1. Pola Triadik Simbol Kekuasaan

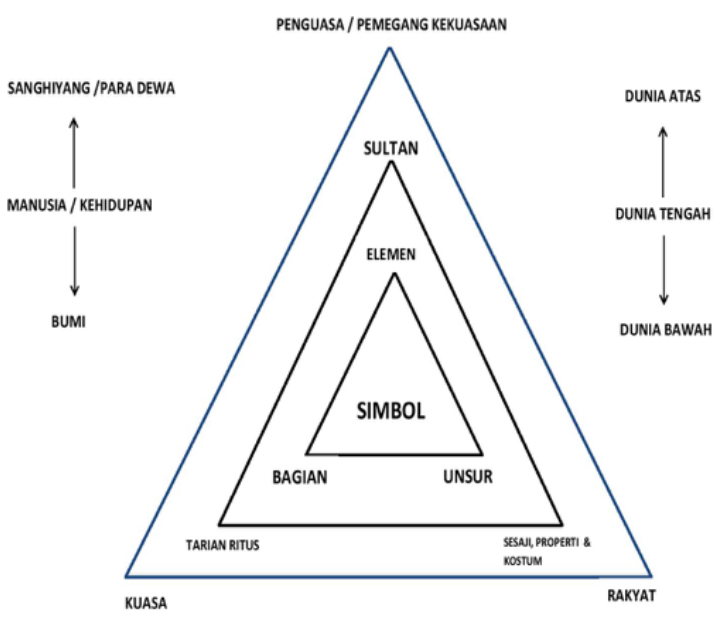

berfungsi sebagai semacam pola yang digunakan untuk menciptakan simbolik bagi kepentingan untuk mengomunikasikan isi upacara (Jakob, 2010, hlm. 15). Menurut Turner (dalam Dillistone, 2002, hlm. 37), sistem triadik atau segitiga bersifat fleksibel menurut konteksnya. Secara konseptual simbol-simbol dilihat melalui posisinya dalam struktur triadik dan karenanya dapat dimanipulasi melalui ketidakhadirannya dan melalui sifat ambivalensi, yang ada dan menjadi sifat hakekatnya, kearah simbol-simbol lain yang berada di sekelilingnya.

Upacara adat Bapelas menjadi wadah reduplikasi dan eksistensi kekuasaan sultan melalui penampakan simbol-simbol property dan perilaku. Oleh karenanya, simbol-simbol yang mencerminkan penunjukan kekuasaan dapat terlihat pada setiap segmen part of part upacara adat Bapelas. Upacara dalam hal ini dianggap sebagai alat mengartikulasikan kekuasaan (sultan) melalui simbol-simbol yang tampak dan menunjukkan identitas sultan melalui eksistensinya di upacara. Identitas memiliki pemahaman bahwa ada ciri, tanda atau jati diri yang melekat pada seseorang, kelompok atau sesuatu sehingga 
membedakan dengan ciri khas orang lain (Santosa, 2014). Kekuasaan kasat mata (dunia atas) maupun kekuasaan (dunia bawah) dan kuasa sultan sebagai panutan rakyat Kutai Kartanegara. Kekuasaan sultan di masa sekarang hanyalah sebagai simbol untuk mempertahankan budaya setempat (lihat Bagan 1).

\section{SIMPULAN}

Upacara adat Bapelas merupakan upacara inti pada festival Erau di Kutai Kartanegara. Reduplikasi Bapelas dilaksanakan untuk memaknai kelahiran sultan sebagai pemegang kekuasaan di Kerajaan Kutai Kartanegara. Jejak leluhur di masa lampau mempunyai kuasa sebagai pencetus jalannya kekuasaan sebuah kerajaan. Meskipun dalam perjalanannya, kekuasaan yang terjadi di Kerajaan Kutai Kartanegara hanya sebagai simbolis kekuasaan di lingkungan masyarakat Kutai dan Kalimantan Timur. Perubahan sistem kekuasaan yang terjadi mengakibatkan kekuasaan sultan tidak memiliki pengaruh yang sangat penting bagi negara. Namun hal ini sangat berkaitan bagi perkembangan ekonomi, politik, dan pariwisata bagi Kalimantan Timur, terutama Kabupaten Kutai Kartanegara sebagai pemegang kekuasaan yang memegang wewenang pemerintahan Republik Indonesia.

Kajian terhadap berbagai unsur yang digunakan dalam upacara dilakukan melalui analisis interpretasi, terutama terhadap simbol-simbol upacara yang digunakan dalam reduplikasi upacara adat Bapelas. Hasil analisis yang telah dilakukan dapat ditarik kesimpulan sebagai berikut: Pertama, bahwa upacara adat Bapelas ini dilaksanakan secara turun-temurun oleh keturunan langsung Keraton Kutai Kartanegara, kerabat terdekat/ jauh dan struktur aparatnya (masih kerabat sultan) sebagai pewaris dari leluhurnya. Pada upacara adat Bapelas terdapat simbol-simbol yang menandakan karakteristik kehidupan masyarakat peladang (pola tiga). Struktur tiga atau pola tiga atau triadik tampak jelas pada simbol-simbol yang digunakan berulang. Konsep ini menjelaskan bahwa dunia atasdunia tengah-dunia bawah merupakan penyatuan dari tiga hal yang berbeda, yaitu langit (dewa-dewa khayangan/sanghiyang), kehidupan manusia (daya-daya transenden), bumi sebagai sumber kehidupan manusia.

Ketiga hal ini adalah sebuah konsep harmoni, sifatnya bukan saling menghancurkan, melainkan saling menghidupkan atau selaras. Masyarakat peladang percaya bahwa di langit ada masyarakatnya, di bumi ada masyarakatnya, dan di tengah adalah kehidupan. Perkawinan keduanya (langit dan bumi) menciptakan entitas ketiga, yakni kehidupan di bumi. Kedua, reduplikasi upacara Bapelas dilakukan oleh pihak Keraton Kutai Kartanegara dan didukung sepenuhnya oleh pemerintah Kabupaten Kutai Kartanegara. Tujuan pemerintah adalah untuk perkembangan pariwisata dan daya tarik di Kutai Kartanegara.

Ketiga, membaca simbol-simbol kekuasaan pada upacara adat Bapelas melalui benda-benda pendukung upacara seperti sesaji, properti, dan lain-lain, bahwa kekuasaan yang dipegang oleh sultan saat ini adalah sebuah kekuasaan yang bersifat 
simbolis (penjaga culture). Hanya berupa legitiminasi (pengakuan) masyarakat kepada sultan sebagai pemegang kekuasaan Kerajaan Kutai Kartanegara. Sultan sebagai raja di Kutai meskipun tidak berkuasa memegang kekuasaan seperti para leluhur sebelumnya, namun sultan tetap mendudukijabatan sebagai raja atau orang yang berkuasa di Kutai, dan masyarakat Kutai masih sangat menjunjung dan menghormati sultan sepenuhnya. Upacara Bapelas telah menunjukkan adanya kerja sama dan kekuasaan yang bersatu padu, saling menghormati antara kekuasaan sultan dan pemerintah kabupaten. Interaksi kedua "penguasa" ini, menunjukkan adanya kehidupan yang harmoni, saling berjalan berdampingan tanpa adanya arogansi kedua belah pihak dan saling mendukung satu sama lain, untuk kepentingan masyarakat Kutai Kartanegara, Kalimantan Timur, dan negara. Keempat, Upacara Bapelas pada dasarnya merupakan upacara yang berbasis kepercayaan kepada atas dewa-dewa langit (sanghiyang) atau Hindu. Upacara ini sudah dilaksanakan sejak zaman raja Mulawarman hingga saat ini. Meskipun kerajaan sekarang menganut agama Islam, namun upacara Bapelas tidak mengalami perubahan dengan mengubah pola upacara mengikuti tata cara agama sultan sekarang. Upacara adat Bapelas dianggap sebagai budaya lokal yang tidak perlu diubah, karena Bapelas merupakan peninggalan leluhur yang wajib di lestarikan. Antara budaya dan agama dalam hal ini berjalan seirama tidak saling mempengaruhi.

\section{UCAPAN TERIMA KASIH}

Terima kasih yang sebesar-besarnya kepada kedua orangtua, keluarga, dan kerabat di Kutai Kartanegara yang banyak membantu untuk penulisan artikel ini. Ucapan terima kasih yang tak terhingga kepada kerabat Keraton Kutai Kartanegara dan jajarannya. Pemerintah Dinas Pariwisata kota Balikpapan, Dinas Pariwisata Kabupaten Kutai Kartanegara, dan Dispenda Kabupaten Kutai Kartaengara yang banyak membantu.

\section{DAFTAR PUSTAKA}

\section{Artikel Jurnal}

Suharno. (2015). Seni Dalam Bingkai Budaya Mistis: Nilai Life Force Dan Transformasinya Ke Budaya Ontologis. Panggung. 25(3), 239.

Santosa, Imam. (2014). Tradisi, Bentuk, Nilai dan Identitas Desain Produk Abad 19-20. Panggung. 24(2). 153.

\section{Buku}

Bachroel, Harry. (2009). Kumpulan Catatan Berhubungan Dengan Adat Kutai Kartanegara Ing Martadipura. Kutai Kartanegara: DISBUDPAR.

Barthes, Roland. (2006). Membedah Mitos-mitos Budaya. Jakarta: Jalasutra.

Bascom, William. (1965). A. Four Function Of Folklor (Alan Dundes. ed). Englewood Cliff: NJ.Prentice Hall. Inc.

Budiarjo, Miriam. (1986). Aneka Pemikiran Tentang Kuasa Dan Wibawa. Surabaya: Pustaka Sinar Harapan.

D, Adham. 2009. Salasilah Kutai. Kutai Kartanegara, Kaltim: Dikbudpar .

Danesi, Marcel. 2011. Pesan, Tanda, Dan Makna Buku Teks Dasar Mengenal Semiotika dan Teori Komunikasi. Yogyakarta: Jalasutra. 
330

Danandjaja, James. 2002. Folklor Indonesia.

Jakarta: PT. Pustaka Utama Grafiti,

DISBUDPAR. 2009. Etnografi Dayak Di

Kabupaten Kutai Kartanegara Provinsi

Kalimantan Timur. Tenggarong:

DISBUDPAR.

Eliade, Mircea. 2002. Sakral Dan Profan.

Yogyakarta: Fajar Pustaka Baru.

Ernest. 1944. Manusia dan Kebudayaan.

Jakarta: PT.Gramedia.

J. Moleong, Lexi. 2011. Metodologi penelitian Kualitatif Edisi Revisi. Bandung: PT. Remaja Rosadakarya.

Moedjanto. 1987. Konsep Kekuasaan Jawa.

Yogyakarta: Kanisius.

Sugiyono. 2008. Metode Penelitian Kunatitatif Kualitatif dan RED. Bandung: Alfabeta.

Sumardjo,Jakob. 2010. Estetika Paradoks (revisi). Bandung: Sunan Ambu PRESS STSI.

Supardan, dadang. 2000. Pengantar Ilmu Sosial: Sebuah Kajian Pendekatan Struktural. Yogyakarta: Bumi Aksara.

\section{Buku Terjemahan:}

Dillistone, F.W. (2002). The Power Of Symbols (terjemahan). Yogyakarta: Kanisius 